\title{
Emotional Mediation of the Comprehension of a Piece of Music
}

\author{
Elena Zvonova \\ Moscow State Pedagogical University \\ Moscow, Russian Federation \\ e-mail: zevreturn@yandex.ru
}

\author{
Ludmila Tarabakina \\ Moscow State Pedagogical University \\ Moscow, Russian Federation \\ e-mail: tarabakina@mail.ru
}

\begin{abstract}
The psychological aspects of the perception and comprehension of a piece of music from the point of view of mediation of a person's emotions in a piece of music are considered in this article.
\end{abstract}

Keywords-emotions; ediation; motional creativity; mbolization; ymbol; tructure; orm of a piece of music

\section{INTRODUCTION: ISSUE OF THE PSYCHOLOGICAL MECHANISM OF MUSIC IMPACT}

Over centuries of civilization's evolution, art has been of primary importance, making it a primary part of culture. In modern science, an opinion has been formed that music exerts a huge influence on a person's development, it has the exclusive facility in education of "a citizen of the world". However, till now, the psychological mechanism of the musical impact on a person remains an actual scientific problem. On the one hand, art as a whole and music specifically, is a product of the symbolical system which develops and functions in accordance with the laws of cultural and historical thinking [1]. The cornerstones of music are the logical laws of an art form. On the other hand, the essence of art is an active, personal and bright emotional experience, an activation of the emotional sphere of a person, which is the least studied part of a person's mentality.

\section{PSYCHOLOGY OF ART AND EMOTIONS}

In his "Psychology of Art", L.S. Vygotskii wrote about the necessity of an objective and analytical method to study a work of art. A work of art itself is structured in a special way of irritants which is consciously directed towards a recipient's reaction [2]. Works of art are a social phenomenon since they are influenced by the whole complex of the social and cultural phenomena of time and keep and transfer an emotional background of experiences of human life. In this regard, music holds a special position as, owing to its natural and temporal specifics, any piece of music keeps the main sensual and emotional characteristics of the generating era.

Emotions are ubiquitous; they accompany all spheres of people's existence and make up the basis of art. Being both a complete and complex structure, the emotional sphere takes an important place in the organization of the inner world and in interpersonal relations; it is closely associated with other psychological characteristics and parts of life. The philosopher S. N. Mareev writes that the problem of ideality of emotions is absolutely absent in modern psychology, it has never been even set. The author considers that this problem was not solved even by L.S. Vygotskii despite his deep analysis of the long history of studying emotions [3]. Indeed, L.S. Vygotskii had not included emotion in a scope of the highest mental functions which he allocated with such attributes as ideality, mediation, arbitrariness, consciousness and instrumentality. Nevertheless, he had divided the social and psychological nature of the functioning of emotions and their social mission as the independent lines of functioning mental commencement, having a different history and nature than mediations and means used in contrast to updating naturally set emotional reactions at the organismic level. He saw the basic mission of emotion psychology in the function of emotions to inspire people to an activity of creative nature and to set high potentials of energy and interests in life. "Emotions would not have been necessary had they been not active ... They were the organizers of behavior for the most hard, fatal and responsible minutes of life. The moment of activity in emotion makes the most important line in the doctrine as for its psychological nature. It is incorrect to think of emotions represented purely by passive experience." - L.S. Vygotskii writes [4]. This postulate of the cultural and historical psychology is of methodological value in studying the nature of emotions, the emotional reaction during the understanding of art included.

\section{THEORETICAL GROUNDS OF STUDY}

Modern studies of perception, understanding and interaction with works of art (V. V. Znakov, V. F. Petrenko, E. V. Ulybina, C. Geertz and others) testify to the effect that the accumulated empirical material demands theoretical generalization to describe the psychological mechanisms of the cognitive process. The urgency of this matter is defined by the prime issue reflected in works of art - that of the value of human life.

With an art form, the creative work overcomes material, with works of art being transformed into the mediated "public world of feeling". A work of art is regarded as a set of esthetic signs directed to excite the expected reciprocal emotional reaction in people. In such context, signs, symbols and structures are not considered as manifestation of the author's state of mind. They act as a conscious organization of a 'person-to-person' communication. Traditionally, studies of a work of art are carried out in two directions: 
either the psychology of an artist, a composer, is being studied and the assumption is being made how personal characteristics have shown themselves in characteristics of their work, or the characteristics of personal perception and creation of an artistic image are investigated. However, the issue of the method of analysis remains open [5].

Art has always accompanied human beings' activity, with a number of cultural and historical symbolical systems having been created. It has been the cultural and historical thinking that has acted as a basis for formation of those systems. A piece of music may be regarded as a result of vigorous creative symbolical activity as replacement, schematization, coding - decoding and modeling. The characteristics of cultural and historical thinking require serious theoretical and experimental studying. The art form and tools of expressiveness of art language may act as abstraction, an empirical attempt to build an ideal, schematized emotional construct.

Cognition of cultural and historical thinking's development is possible not only with archival documents and artifacts but with ethnographic and cross-cultural researches, which are of high empirical potential. When the specifics of cultural and historical thinking types are being studied, we are not focused on the public consciousness but on typical, invariant cogitative operations of an individual. We are not interested in changing the thinking content, but in changing the structure of the thought processes themselves [6]. J. S. Bruner marks out two groups of the cultural factors which have the most influence on thinking, the value orientations and factors relevant to various aspects of language and its use [7].

However, the linguistic approach in the analyses of cultural and historical thinking types cannot be exhaustive since personal thought processes never occur completely verbal [8]. To study and understand the left brain thinking, R. Barthes called upon an analysis of the environment. He considered that it is necessary to regard an environment as 'a set of cogitative habits' [9].

Pieces of music embody the emotionally significant social phenomena in artistic images. The figurative nature of art is deeply symbolical. The emergence of a symbol defines the attempt of a person to learn something difficult and incognizable. The area of symbols includes all super sensual, unconscious symbols, since, in the last analysis, the semiotics function is that of the human reason, which has been born because of the impossibility to stop and be satisfied with a 'literal sense' of things, a requirement to always add some extended sense [10].

Theoretical researches of a turn of the 20th to $21 \mathrm{st}$ centuries show the tendency to expand the complex systems of human thinking with an 'interaktsional effect', designing magnitudes of a higher level. The huge part is assigned to culture (R. Barthes, Michael D. Cole, C. Geertz, S. K. Langer, and Br. Shore). With the embodiment of the essence of a describable phenomenon, the symbolical character of art language allows new parallels, senses and meanings being involved. C. Geertz considers that the metaphoricalness of thinking rests on a basis of cultural models which provide an external source of nervous system regulation [11]. Cultural (or conventional) models provide the ground for synchronizing associations which tag the corresponding bounds for interpretation of a real experience. The cultural model's role in the organization of thinking by no means implies either solidity or historicity of cultural cognition because the double birth of culture signs guarantees their dual nature as conventional and dynamic [12].

The analysis of the interactions of a person and a piece of music by the way of analyzing the communicative message demanding some emotional reaction allows marking out facilities to materialize the author's plan, the examination of understanding art as a thinking component; analyzing the communication conditions through the change or unity of musical and theoretical systems of a piece of music and the incorporated context culture. All types and forms of interaction of a person and a work of art (composition, interpretation and perception) are the creative process of an artistic image. It is possible to study psychological characteristics of an artistic image through an emotional creativity phenomenon.

The origin of a special partiality and an intensive interest in the necessity to carry out non-standard tasks has received the name of the emotional creativity in literature. In J. R. Averill's theory of that creativity, a person is considered as an active subject who is purposefully changing him/herself and reality around. Emotions, which in themselves are creative activity's products, have been named. J. R. Averill insists that emotional creativity does not arise from blank but is the acme of perfection generated by certain efforts. An emotionally creative person (or group) is described as friendly subject inclined to an inquiry, sensitive to contradictions and keeping resilience to overcome problems. Emotional creativity has a set of points that intersect with resilience. Resilience as theoretical construct is much wider than emotional creativity because it covers different spheres of mentality: cognitive, motivational, emotional, volitional and personal. However, it is emotional creativity that generates resilience and not the opposite. The existence of resilience does not guarantee emotional creativity while the latter functionally initiates the qualities which are necessary for resilience formation and its level [13]. Emotional creativity and openness to new experiences are noted to be the nature only for groups which are psychologically uniform in their structure [14].

\section{CONCLUSION}

Conceptual postulates of cultural and historical thinking and culture types allow marking out characteristics of groups' psychological uniformity. The understanding of a piece of music acts as the cognitive and emotional reaction to the system of specially organized sign and symbolical means.

\section{REFERENCES}

[1] E. V. Zvonova. Theoretical bases of the cultural and historical analysis of a piece of music//European Social Science Journal. Moscow, International Research Institute, 2011, No. 7, pp. 66-74.

[2] L. S. Vygotskii. Psychology of Art. M., Pedagogics, 1987. 
[3] Mareev S. N. From Kant and Kassirer to Il'enkov: the Issue of Ideality of Human Feelings// Approaches to Philosophy, 2009, No. 9. Pp. 142-152.

[4] L. S. Vygotskii. Training of Emotional Behavior//Pedagogical psychology / edited by V. V. Davydov. M., Pedagogics, 1991, pp. 128-144.

[5] L. S. Vygotskii. Psychology of Art. M., Pedagogics, 1987.

[6] P. Tul'viste. Cultural and Historical Development of Verbal Thinking, (psychological study), Tallinn, Valgus, 1987.

[7] Bruner J. S. Processes of Cognitive Growth: Infancy. Vol. 3, Heinz Werner Lecture Series, Worcester, Mass., Clark University Press, 1969.

[8] P. Tul'viste. Cultural and Historical Development of Verbal Thinking, (psychological study), Tallinn, Valgus, 1987.

[9] R. Barthes. Introduction a l'Analyse Structurale des Recits//Communications 8, Paris, 1966

[10] G. Durand. Les Structures Anthropologiques de l'Imaginaire. Paris, Dunod, 1997.

[11] C. Geertz. The Interpretation of Cultures. New York, Basic books, 1973.

[12] Br. Shore. Twice-born, Once Conceived: Meaning Construction and Cultural Cognition//American Anthropologist, 93, No. 1, March 1991, pp. 9-27.

[13] J. R. Averill. Emotions as Mediators and as Products of Creative Activity. In: J. Kaufman \& J. Baer (Eds.). Creativity across Domains: Face of Muse. Mahwah, N.Y., Erlbaum, 2005. 225-243.

[14] A. Fernkhem and P. Heyven. Lichnost and social behavior. SPb., Piter, 2001 . 